\title{
Acne Vulgaris in Jeddah Medical Students: Prevalence, Severity, Self-Report, and Treatment Practices
}

\author{
Shadi Zari ${ }^{1,2}$, Asraa Turkistani ${ }^{3}$ \\ ${ }^{1}$ Department of Dermatology, Faculty of Medicine, University of Jeddah, Jeddah, Saudi Arabia \\ ${ }^{2}$ Division of Dermatology, Faculty of Medicine, McGill University, Montreal, Canada \\ ${ }^{3}$ Faculty of Medicine, King Abdulaziz University, Jeddah, Saudi Arabia \\ Email: shadizarimd@gmail.com
}

How to cite this paper: Zari, S. and Turkistani, A. (2017) Acne Vulgaris in Jeddah Medical Students: Prevalence, Severity, SelfReport, and Treatment Practices. Journal of Cosmetics, Dermatological Sciences and Applications, 7, 67-76. https://doi.org/10.4236/jcdsa.2017.71007

Received: January 23, 2017

Accepted: March 10, 2017

Published: March 13, 2017

Copyright (c) 2017 by authors and Scientific Research Publishing Inc. This work is licensed under the Creative Commons Attribution International License (CC BY 4.0).

http://creativecommons.org/licenses/by/4.0/ (c) (i) Open Access

\begin{abstract}
Acne is a common skin disorder of teenagers and continues into adulthood. Research has been limited regarding acne prevalence, perception and health care utilization in Saudi Arabia. The objective of this study was to assess acne prevalence in final year female medical students in Jeddah, Saudi Arabia using the global acne grading system (GAGS) compared with student's self-report of their acne. This is a cross-sectional study conducted among 151 students during 2016, in which students were interviewed subjectively and examined objectively by a trained physician. This study showed that acne was reported subjectively by $83.4 \%$ of female students compared to $98 \%$ of students assessed objectively by the global acne grading system. $14.6 \%$ of students claimed having no acne while it was objectively present, which was statistically significant $\left(\mathrm{X}^{2}=15.4, \mathrm{P}<0.001\right) .41 \%$ visited a dermatologist and $28.5 \%$ waited 1 year until seeking a dermatologist. However, $35.8 \%$ of students got an overthe-counter drug for their acne. Surprisingly, treatment duration expectation was $<1$ week in $9.9 \%$ compared to $>2$ months in $39.1 \%$ of students. Acne was present in $41.1 \%$ of the students parents compared to $83.4 \%$ in their siblings. A total of $41.7 \%$ of student had trunk acne. $60.9 \%$ of students had scarring and $72.8 \%$ of them had pigmentation. Moderate to severe acne students had higher siblings acne history of $95.2 \%\left(\mathrm{X}^{2}=5.85, \mathrm{P}<0.05\right)$, higher scaring of $73.8 \%\left(\mathrm{X}^{2}=4.05, \mathrm{P}<0.05\right)$, and higher pigmentation of $85.7 \%\left(\mathrm{X}^{2}=4.87, \mathrm{P}<\right.$ $0.05)$ which was statistically significant. Our study confirms that acne is very common in female medical students in Jeddah, Saudi Arabia with a prevalence rate of $98 \%$. Knowledge regarding acne treatment was inadequate demonstrating the need for educational and awareness programs about early treatment that will prevent suffering from acne scarring or pigmentation.
\end{abstract}




\section{Keywords}

Acne, Acne Vulgaris, Acne Prevalence, Acne Treatment, Acne Self-Report

\section{Introduction}

Acne is one of the most common inflammatory chronic skin diseases that affect teenagers and continues into adulthood. Women are most commonly affected with a mean age for presentation of 24 years [1]. In the US, the prevalence rate of acne is $85 \%$ in those aged 12 to 24 years [2]. Only a small percentage of acne patients are treated by a dermatologist or prescribed medications [3]. While there is no associated mortality with acne, suffering mainly is due to permanent scarring, post inflammatory hyperpigmentation and poor self-image [4]. Various studies on acne prevalence showed that patients have a greater degree of acne severity if there is first-degree relative's acne history [5] [6]. There are many studies on twins and families that proved that a first-degree relative acne history has a strong influence on age of onset, severity and treatment [7]. There is abundance in the availability of over the counter (OTC) skin care products in pharmacies and centers promoted to the public. Without seeing a dermatologist, patients will choose OTC treatments that may not control their acne [8]. Inflammatory acne lesions can result in permanent scars, the severity of which may be affected by delay in treatment and by the degree of acne severity [9] [10].

Also, there is relatively few information in the medical literature on the prevalence, clinical severity and self-report of acne among medical students in Saudi Arabia. This study reports the prevalence and clinical severity of acne in comparison with the self-report of acne in final year female medical students in King Abdulaziz University Hospital (KAUH) in Jeddah, Saudi Arabia. The secondary outcome measures of the percentage of students who visited a dermatologist, how long they waited before seeking treatment, percentage of students who got an OTC drug, treatment duration expectation, family history of acne in parents and siblings, most common areas affected by acne, and the percentage of scarring and pigmentation resulting from their acne were recorded in a questionnaire.

\section{Methods}

A questionnaire-based cross-sectional study was conducted among 151 final year female medical students attending the medical faculty at King Abdulaziz University during 2016 followed by an objective evaluation of their acne (see Appendix). The study was approved by the Ethics Committee at KAUH and the Research Committee at the University of Jeddah Faculty of Medicine.

Final year female medical students were interviewed using a confidential, anonymous interviewing questionnaire to collect personal data, knowledge, percep- 
tion and practice regarding their acne. After students oral consent, they were given a questionnaire to complete. All the students completed the questionnaire that was distributed to them. Upon completion of the questionnaire by students, an intern who was trained earlier by the consultant dermatologist examined the students for the presence of acne lesions. The trained intern then graded the acne severity and was blinded to the study outcome.

Clinical classification of acne severity was done using the Global Acne Grading System (GAGS). Each type of lesion was given a value depending on severity: no lesions $=0$, comedones $=1$, papules $=2$, pustules $=3$ and nodules $=4$. The score for each area (Local score) is calculated using the formula: Local score = Factor $x$ Grade $(0-4)$. The global score is the sum of local scores, and acne severity was graded using the global score. A score of $1-18$ is considered mild; 19 - 30, moderate; 31 - 38, severe; and $>39$, very severe [11].

\section{Statistical Methods}

According to the GAGS, students were classified into four groups: None, mild, moderate, and severe acne. Individuals with moderate and severe acne were included in one group for some evaluations. The primary outcomes of the study were the prevalence and clinical severity of acne in comparison with the selfreport of acne in final year female medical students in Jeddah, Saudi Arabia.

The association between clinical acne grade as the dependent variable and other factors as explanatory variables were analyzed by chi-squared test. Analysis of data was done using SPSS Version 13 (SPSS, Inc., Chicago, IL, USA). Data were presented by OR and $95 \%$ CI. P values of $<0.05$ were considered statistically significant.

\section{Results}

\subsection{Acne Severity}

Using the GAGS to examine the students, acne was present in 148/151 (98\%) of female medical students involved in the study. 106/151 (70.2\%) had mild acne, and $36 / 151(23.8 \%)$ moderate, and 6/151 (4\%) had severe acne present (Table $1)$.

\subsection{Acne Self-Rating by Students}

According to the Acne self-rating question in the questionnaire, 126 out of 151 (83.4\%) medical students have acne. As 91/151 (60.3\%), 30/151 (19.9\%) and $5 / 151(3.3 \%)$ rated their acne as mild, moderate and severe respectively (Table 2).

Comparing between patient self-assessment and objectively assessing patient acne by the global acne grading system, it was found in our study that $14.6 \%$ (22 students) claimed to have no acne while they were having acne objectively which was statistically significant $\left(\mathrm{X}^{2}=15.426, \mathrm{P}<0.001\right), \mathrm{OR}=6.727$ (95\% CI 4.575 9.892) (Table 3). 
Table 1. Grade of acne severity.

\begin{tabular}{cccc}
\hline & Frequency & Percent & Cumulative Percent \\
\hline None & 3 & 2.0 & 2.0 \\
Mild & 106 & 70.2 & 72.2 \\
Moderate & 36 & 23.8 & 96.0 \\
Severe & 6 & 4.0 & 100.0 \\
Total & 151 & 100.0 & \\
\hline
\end{tabular}

Table 2. How would you rate your current acne?

\begin{tabular}{cccc}
\hline & Frequency & Percent & Cumulative Percent \\
None & 25 & 16.6 & 16.6 \\
Mild & 91 & 60.3 & 76.8 \\
Moderate & 30 & 19.9 & 96.7 \\
Severe & 5 & 3.3 & 100.0 \\
Total & 151 & 100.0 & \\
\hline
\end{tabular}

Table 3. Objective assessment vs. self assessment cross tabulation.

\begin{tabular}{|c|c|c|c|c|c|}
\hline & & & \multicolumn{2}{|c|}{ Self assessment } & \multirow{2}{*}{ Total } \\
\hline & & & None & Acne & \\
\hline & & Count & 3 & 0 & 3 \\
\hline \multirow{4}{*}{$\begin{array}{l}\text { Objective } \\
\text { assessment }\end{array}$} & None & $\%$ within objective assessment & $100.0 \%$ & $0.0 \%$ & $100.0 \%$ \\
\hline & & Count & 22 & 126 & 148 \\
\hline & Acne & & & & \\
\hline & & $\%$ within objective Assessment & $14.9 \%$ & $85.1 \%$ & $100.0 \%$ \\
\hline \multirow{3}{*}{\multicolumn{2}{|c|}{ Total }} & Count & 25 & 126 & 151 \\
\hline & & & & & \\
\hline & & $\%$ within objective Assessment & $16.6 \%$ & $83.4 \%$ & $100.0 \%$ \\
\hline
\end{tabular}

\subsection{Acne Location}

Our study conduct showed a total of $63(41.7 \%)$ students with truncal acne (chest and back). 54 students have more acne on their back compared to 33 students who had more acne on their chest area (Table 4), as some students had acne both on their chest and back areas. 85 out of 151 (56.3\%) have acne present in more than one area on the face. For acne localized in one area only, it was most commonly present on the forehead 21/151 (13.9\%) (Table 5).

\subsection{Acne Treatment Practices}

Only 62 out of 151 (41\%) students visited a dermatologist regarding their acne (Table 4). 43/151 (28.5\%) of students waited 1 year before seeing a dermatolo- 
gist (Table 6). 54 out of $151(35.8 \%)$ students got an acne treatment without a prescription (Table 4).

\subsection{Acne Treatment Duration Expectation}

The treatment duration expectation was less than 1 week in 15/151 (9.9\%) of students compared to more than 2 months in 59/151 (39.1\%) (Table 7).

\subsection{Acne Family History}

Acne was present in 62/151 (41.1\%) of the students parents compared to $126 / 151$ $(83.4 \%)$ in their siblings (Table 4). For student with moderate to severe acne, the higher percentage of siblings history of $95.2 \%$ (40/42) was statistically significant $\left(\mathrm{X}^{2}=5.859, \mathrm{P}=0.016\right), \mathrm{OR}=0.187(95 \% \mathrm{CI} 0.042$ - 0.832) (Table 8).

Table 4. Response of students to questionnaire.

\begin{tabular}{|c|c|c|c|c|c|}
\hline Questionnaire Number (QN) & Variable & Yes & No & Total & $P$ value $X^{2}$ test \\
\hline 2 & Presence of acne on the back & 54 & 97 & 151 & $<0.001$ \\
\hline 3 & Presence of acne on the chest & 33 & 118 & 151 & $<0.001$ \\
\hline 5 & Visiting a dermatologist regarding acne & 62 & 89 & 151 & 0.028 \\
\hline 6 & Getting acne treatment without a prescription & 54 & 97 & 151 & $<0.001$ \\
\hline 9 & Acne presence in parents & 62 & 89 & 151 & 0.028 \\
\hline 10 & Acne presence in siblings & 126 & 25 & 151 & $<0.001$ \\
\hline 11 & Presence of scars & 92 & 59 & 151 & 0.007 \\
\hline 12 & Presence of post inflammatory hyperpigmentation & 110 & 41 & 151 & $<0.001$ \\
\hline
\end{tabular}

Table 5. Response of students to acne location on the face.

\begin{tabular}{ccccccccccc}
\hline QN & Variable & None & Forehead & Right cheek & Left cheek & Nose & Chin & More than one side & Total & P value X test \\
\hline 4 & $\begin{array}{c}\text { Acne location } \\
\text { on the face }\end{array}$ & 14 & 21 & 5 & 10 & 3 & 13 & 85 & 151 & $<0.001<$ \\
\hline
\end{tabular}

Table 6. Response of students to duration until seeking a dermatologist.

\begin{tabular}{ccccccccc}
\hline QN & Variable & None & $\begin{array}{c}\text { Less than } \\
3 \text { months }\end{array}$ & $\begin{array}{c}3 \text { to } 6 \\
\text { months }\end{array}$ & $\begin{array}{c}6 \text { to } 12 \\
\text { months }\end{array}$ & $\begin{array}{c}\text { More than } \\
\text { one year }\end{array}$ & $\begin{array}{c}\text { Total value } \\
\mathrm{X}^{2} \text { test }\end{array}$ \\
\hline 7 & $\begin{array}{l}\text { Waiting before } \\
\text { seeing a doctor }\end{array}$ & 47 & 15 & 28 & 18 & 43 & $151<$ & $<0.001$ \\
\hline
\end{tabular}

Table 7. Response of students regarding treatment duration expectation.

\begin{tabular}{ccccccccc}
\hline QN & Variable & None & $\begin{array}{c}\text { Less than } \\
1 \text { week }\end{array}$ & $\begin{array}{c}1 \text { week to } \\
1 \text { month }\end{array}$ & $\begin{array}{c}1-2 \\
\text { months }\end{array}$ & $\begin{array}{c}\text { More than } \\
2 \text { months }\end{array}$ & $\begin{array}{c}\text { Total } \\
\text { Xalue } \\
\mathrm{X}^{2} \text { test }\end{array}$ \\
\hline 8 & $\begin{array}{c}\text { Acne treatment } \\
\text { duration expectation }\end{array}$ & 24 & 15 & 27 & 26 & 59 & $151<<0.001$ \\
\hline
\end{tabular}




\subsection{Presence of Scarring and Post-Inflammatory Hyperpigmentation}

Scars were present in 92/151 (60.9\%) of students (Table 4). Post inflammatory hyperpigmentation (PIH) was present in 110/151 (72.8\%) of students (Table 4). In moderate to severe acne students, $73.8 \%(31 / 42)$ had scaring and $85.7 \%$ (36/42) had PIH which was statistically significant $\left(\mathrm{X}^{2}=4.056, \mathrm{P}=0.044\right), \mathrm{OR}=$ 0.451 (95\% CI 0.206 - 0.989) (Table 9) and $\left(\mathrm{X}^{2}=4.87, \mathrm{P}=0.027\right), \mathrm{OR}=0.352$ (95\% CI 0.136 - 0.914) (Table 10) respectively.

Table 8. Modified acne grading vs. brothers and sisters acne.

Risk Estimate

\begin{tabular}{lccc} 
& Value & \multicolumn{2}{c}{$95 \%$ Confidence Interval } \\
\cline { 4 - 4 } & & Upper & Lower \\
\hline $\begin{array}{l}\text { Odds ratio for modified grading } \\
\text { (none \& mild vs. moderate \& severe) }\end{array}$ & 0.187 & 0.042 & 0.832 \\
For cohort brothers and sisters acne (none \& mild) & 0.828 & 0.736 & 0.932 \\
For cohort brothers and sisters acne (moderate \& severe) & 4.431 & 1.092 & 17.976 \\
Number of valid cases & 151 & & \\
\hline
\end{tabular}

Table 9. Modified acne grading vs. scars.

\begin{tabular}{lccc}
\hline & Risk Estimate & & \\
& & & \\
& & & \\
& Value & Confidence Interval \\
\cline { 3 - 4 } & & Upper & Lower \\
\hline $\begin{array}{l}\text { Odds ratio for modified grading } \\
\text { (none \& mild vs. moderate \& severe) }\end{array}$ & 0.451 & 0.206 & 0.989 \\
For cohort scars (none \& mild) & & & 0.969 \\
For cohort scars (moderate \& severe) & 0.758 & 0.593 & 2.914 \\
Number of valid cases & 1.681 & 0.970 & \\
\end{tabular}

Table 10. Modified acne grading vs. pigmentation.

\begin{tabular}{|c|c|c|c|}
\hline \multicolumn{4}{|c|}{ Risk Estimate } \\
\hline & \multirow{2}{*}{ Value } & \multicolumn{2}{|c|}{$95 \%$ Confidence Interval } \\
\hline & & Upper & Lower \\
\hline $\begin{array}{l}\text { Odds ratio for modified grading } \\
\text { (none \& mild vs. moderate \& severe) }\end{array}$ & 0.352 & 0.136 & 0.914 \\
\hline For cohort pigmentation (none \& mild) & 0.792 & 0.662 & 0.947 \\
\hline For cohort pigmentation (moderate \& severe) & 2.248 & 1.021 & 4.950 \\
\hline Number of valid cases & 151 & & \\
\hline
\end{tabular}




\section{Discussion}

Acne prevalence was reported to be $85 \%$ in the population age of 12 to 24 years [2] [12] [13]. On the acne self-assessment questionnaire, acne was reported by $83.4 \%$ of students compared to $98 \%$ by the physician's examination. Menon showed acne prevalence determined by the trained observer to be 0.55 (95\% CI 0.49 - 0.61), while Self-reported acne prevalence was 0.43 (95\% CI 0.37 - 0.49). Not many studies in the literature have analyzed the validity of self-reported acne in comparison with the trained observer diagnosis of acne. The few studies that looked at this problem concluded that there is lack of agreement between self-report and the trained observer acne evaluation, which is similar to our study [14].

Our study showed that $41.7 \%$ of students had truncal acne (chest and back). This goes with a previous study that showed that $41 \%$ of women have truncal acne [15]. Our study also showed that acne is present more on the back than on the chest area. This shows the importance of always examining the back of an acne patient by the treating physician, to prevent unnecessary scarring from a delay in treating back lesions.

Moderate and severe acne students in our study had a higher percentage in seeking a dermatologist regarding their acne. $28.5 \%$ of students in our study waited more than 1 year to see a dermatologist. Although there is an abundant availability of acne treatments, there is underutilization of them. According to one study, treatment of acne is used in only $18 \%$ of adolescents suffering from acne [16]. Our study showed that $35.8 \%$ of students got an acne treatment without a prescription; which are most probably over the counter drugs. This is comparable to the general estimation that $30 \%$ of affected acne patients are likely to use OTC treatments [14]. Surprisingly the treatment duration expectation was less than one week in $9.9 \%$ of students and more than 2 months in $39.1 \%$ of students only. Based on these numbers, there should be more education regarding the time required to see a full response to medications, which is usually 2 to 3 months [17].

Our study is compatible with another study that showed undergraduate students to have acne by $78 \%$ heritability in first-degree relative's [18]. Previous studies showed that moderate to severe acne were strongly associated with firstdegree relative's acne history [5] [19]. Students in our study with moderate to severe acne had a higher percentage of sibling's history of $95.2 \%$.

Our study showed that scaring was present in $60.9 \%$ of our student's population, in which we postulate that not seeking a dermatologist for treatment is the main reason. A large percentage of students had post inflammatory hyperpigmentation (72.8\%); which is likely due to the Middle Eastern ethnic group; who are mostly Fitzpatrick skin types 3 and 4. Also, using over the counter treatments such as exfoliating products or strong toners can contribute to $\mathrm{PIH}$ by causing skin irritation [20]. This is why designing a treatment regimen individualized for every patient will help reducing PIH and increasing the patient satisfaction. Our students with moderate to severe acne revealed that $85.7 \%$ of them 
had PIH. A study done by the Asian acne board showed that $58.2 \%$ of patients in their study had PIH [21]. The higher percentage of PIH in our study may be explained again because of darker Fitzpatrick skin types in Arabian skin compared to Asian skin.

One of the limitations of our study is that all the students are females with no male participants. We believe that the results from our female study sample are representative of females in Saudi Arabia of a similar age group. The high acne prevalence in our study compared to other studies may be due to the fact that it was done in a classroom setting and was not clinic based, which allowed us to include many students with mild acne who would not usually seek medical advice. Acne is usually considered a disorder of adolescence. However, there are not many data on the prevalence of acne in the adult population [22]. Although acne is best assessed by a dermatological examination, standardized diagnostic criteria are not available [23].

\section{Conclusion}

Our study confirms that acne is very common in female medical students in Jeddah, Saudi Arabia with a prevalence rate of $98 \%$. This is the first study in Saudi Arabia to compare acne prevalence and severity using an objective assessment by the GAGS compared to the students self-report of acne. Our study showed a discrepancy between the self-assessment of acne and objective assessment by the physician. Our study also showed that there is a delay in seeking medical advice and that students with higher acne grade were more likely to visit a dermatologist. The importance of having patient's knowledge and treatment practices regarding their acne is fundamental in creating awareness about the treatments effectiveness. This will also lead to the prevention of unnecessary suffering from acne scaring or pigmentation, which was highly prevalent in patients with moderate to severe acne in our study.

\section{Acknowledgements}

Thanks to Prof. Talal Zari for performing the statistical analysis for this study.

\section{References}

[1] Preneau, S. and Dreno, B. (2012) Female Acne-A Different Subtype of Teenager Acne? Journal of the European Academy of Dermatology and Venereology, 26, 277282. https://doi.org/10.1111/j.1468-3083.2011.04214.x

[2] Bhate, K. and Williams, H.C. (2013) Epidemiology of Acne Vulgaris. British Journal of Dermatology, 168, 474-485. https://doi.org/10.1111/bjd.12149

[3] Bowe, W.P. and Shalita, A.R. (2008) Effective Over-the-Counter Acne Treatments. Seminars in Cutaneous Medicine and Surgery, 3, 170-176.

https://doi.org/10.1016/j.sder.2008.07.004

[4] Zaenglein, A.L., et al. (2016) Guidelines of Care for the Management of Acne Vulgaris. Journal of the American Academy of Dermatology, 74, 945-973. https://doi.org/10.1016/j.jaad.2015.12.037

[5] Di Landro, A., et al. (2012) Family History, Body Mass Index, Selected Dietary Fac- 
tors, Menstrual History, and Risk of Moderate to Severe Acne in Adolescents and Young Adults. Journal of the American Academy of Dermatology, 67, 1129-1135.

[6] Tan, H.H., Tan, A.W., Barkham, T., Yan, X.Y. and Zhu, M. (2007) CommunityBased Study of Acne Vulgaris in Adolescents in Singapore. British Journal of Dermatology, 157, 547-551. https://doi.org/10.1111/j.1365-2133.2007.08087.x

[7] Karciauskiene, J., Valiukeviciene, S., Stang, A. and Gollnick, H. (2014) The Prevalence and Risk Factors of Adolescent Acne among Schoolchildren in Lithuania: A Cross-Sectional Study. Journal of the European Academy of Dermatology and Venereology, 28, 733-740. https://doi.org/10.1111/jdv.12160

[8] Del Rosso, J.Q., Gold, M., Rueda, M.J., Brandt, S. and Winkelman, W.J. (2015) Efficacy, Safety, and Subject Satisfaction of a Specified Skin Care Regimen to Cleanse, Medicate, Moisturize, and Protect the Skin of Patients Under Treatment for Acne Vulgaris. The Journal of Clinical and Aesthetic Dermatology, 8, 22.

[9] Fabbrocini, G., et al. (2010) Acne Scars: Pathogenesis, Classification and Treatment. Dermatology Research and Practice, 2010, Article ID: 893080.

[10] Shamban, A.T. and Narurkar, V.A. (2009) Multimodal Treatment of Acne, Acne Scars and Pigmentation. Dermatologic Clinics, 27, 459-471. https://doi.org/10.1016/j.det.2009.08.010

[11] Doshi, A., Zaheer, A. and Stiller, M.J. (1997) A Comparison of Current Acne Grading Systems and Proposal of a Novel System. International Journal of Dermatology, 36, 416-418. https://doi.org/10.1046/j.1365-4362.1997.00099.x

[12] Burton, J.L., Cunliffe, W.J., Stafford, I. and Shuster, S. (1971) The Prevalence of Acne Vulgaris in Adolescence. British Journal of Dermatology, 85, 119-126. https://doi.org/10.1111/j.1365-2133.1971.tb07195.x

[13] Tan, J.K. and Bhate, K. (2015) A Global Perspective on the Epidemiology of Acne. British Journal of Dermatology, 172, 3-12. https://doi.org/10.1111/bjd.13462

[14] Menon, C., Gipson, K., Bowe, W.P., Hoffstad, O.J. and Margolis, D.J. (2008) Validity of Subject Self-Report for Acne. Dermatology, 217, 164-168. https://doi.org/10.1159/000136655

[15] Dumont-Wallon, G. and Dreno, B. (2008) Specificity of Women Older than 25 Years of Age. Presse Medicale, 37, 585-591. https://doi.org/10.1016/j.lpm.2007.07.014

[16] Cheng, C.E., Irwin, B., Mauriello, D., Liang, L., Pappert, A. and Kimball, A.B. (2010) Self-Reported Acne Severity, Treatment, and Belief Patterns across Multiple Racial and Ethnic Groups in Adolescent Students. Pediatric Dermatology, 27, 446-452. https://doi.org/10.1111/j.1525-1470.2010.01286.x

[17] Feldman, S., Careccia, R.E., Barham, K.L. and Hancox, J. (2004) Diagnosis and Treatment of Acne. American Family Physician, 69, 2123-2130.

[18] Wei, B., et al. (2010) The Epidemiology of Adolescent Acne in North East China. Journal of the European Academy of Dermatology and Venereology, 24, 953-957. https://doi.org/10.1111/j.1468-3083.2010.03590.x

[19] Ballanger, F., Baudry, P., N’Guyen, J.M., Khammari, A. and Dréno, B. (2006) Heredity: A Prognostic Factor for Acne. Dermatology, 212, 145-149. https://doi.org/10.1159/000090655

[20] Alexis, A.F. (2014) Acne Vulgaris in Skin of Color: Understanding Nuances and Optimizing Treatment Outcomes. Journal of Drugs in Dermatology, 13, s61-s65.

[21] Abad-Casintahan, F., et al. (2016) Frequency and Characteristics of Acne-Related Post-Inflammatory Hyperpigmentation. The Journal of Dermatology, 43, 826-828. https://doi.org/10.1111/1346-8138.13263 
[22] Goulden, V., Stables, G.I. and Cunliffe, W.J. (1999) Prevalence of Facial Acne in Adults. Journal of the American Academy of Dermatology, 41, 577-580.

[23] Schäfer, T., Nienhaus, A., Vieluf, D., Berger, J. and Ring, J. (2001) Epidemiology of Acne in the General Population: The Risk of Smoking. British Journal of Dermatology, 145, 100-104. https://doi.org/10.1046/j.1365-2133.2001.04290.x

\section{Appendix}

\section{Questionnaire content distributed to medical students:}

1) How would you rate your current acne?

1. $\square$ None 2. $\square$ Mild 3. $\square$ Moderate 4. $\square$ Severe

2) Do you have pimples in your back?

1. $\square$ Yes 2. $\square$ No

3) Do you have pimples in your chest?

1. $\square$ Yes 2. $\square$ No

4) Where is the location of your acne on the face?

0. none 1. $\square$ forehead 2. $\square$ Right cheek 3. $\square$ Left cheek

4. $\square$ Nose 5. $\square$ Chin 6. More than one side

5) Have you visited a dermatologist regarding your acne in the past year?

1. $\square$ Yes 2. $\square$ No

6) Have you visited a pharmacy and got medicine without a prescription?

1. $\square$ Yes 2. $\square$ No

7) How long did you wait before seeing a doctor?

0. none 1. $\square$ Less than 3 months 2. $\square 3$ to 6 months

3. $\square 6$ to 12 months 4. $\square$ More than 1 year

8) How long do you expect your acne treatment to take?

0. none 1. $\square$ Less than 1 week $\quad 2$. $\square 1$ week to 1 month

3. $\square 1$ - 2 months 4. $\square$ more than 2 months

9) Did any of your parents have acne in the past?

1. $\square$ Yes 2. $\square$ No

10) Did any of your brothers and sisters have acne in the past?

1. $\square$ Yes 2. $\square$ No

11) Is your acne causing any scars?

1. $\square$ Yes 2. $\square$ No

12) Is your acne causing any pigmentation?

1. $\square$ Yes 2. $\square$ No 
Submit or recommend next manuscript to SCIRP and we will provide best service for you:

Accepting pre-submission inquiries through Email, Facebook, LinkedIn, Twitter, etc. A wide selection of journals (inclusive of 9 subjects, more than 200 journals)

Providing 24-hour high-quality service

User-friendly online submission system

Fair and swift peer-review system

Efficient typesetting and proofreading procedure

Display of the result of downloads and visits, as well as the number of cited articles Maximum dissemination of your research work

Submit your manuscript at: http://papersubmission.scirp.org/

Or contact jcdsa@scirp.org 